\title{
Multiple variations of azygos system of veins: a case report
}

\author{
MALOOR, P. A., NAYAK, S. B. * REGHUNATHAN, D., SHETTY, \\ S. D. and PRABHU, G. S. \\ Melaka Manipal Medical College (Manipal Campus), Manipal University, Madhav Nagar, \\ Manipal, Karnataka, India \\ *E-mail: nayaksathish@gmail.com
}

\begin{abstract}
Azygos venous system drains the venous blood from thoracic wall. Knowledge of variations of its course and tributaries is important to cardiothoracic surgeons, radiologists and orthopedic surgeons. We observed the following variations in the azygos veins. Both azygos and hemiazygos veins were formed by union of lumbar azygos and subcostal veins of corresponding sides. The ascending lumbar vein did not drain into the azygos system. The hemiazygos vein had a larger diameter than the lower part of azygos vein and it joined azygos vein at the level of seventh thoracic vertebra. Accessory hemiazygos vein was totally absent. The azygos vein received 4 th to 11 th right posterior intercostal veins and also received 3rd to 6th left posterior intercostal veins. Hemiazygos vein received 7 th to 11 th left posterior intercostal veins.
\end{abstract}

Keywords: azygos vein, hemiazygos, accessory hemiazygos vein, anatomic variation.

\section{Introduction}

Anomalies of azygos vein have been well studied and documented (MEZZOGIORNO and PASSIATORE, 1988). Most of the anomalies are due to the developmental reasons (PILLET, MERCIER, CRONIER et al., 1986; COSCINA, ARGER, MINTZ et al., 1986; MEZZOGIORNO and PASSIATORE, 1988). The azygos system of veins is derived from vertical venous channels called 'azygos line of veins'. During development, the azygos lines are parallel to another two venous channels called subcardinal and postcardinal veins. Lower major part of the azygos vein develops from the right azygos line, whereas the arch of azygos vein develops from the cranial part of the right postcardinal and common cardinal veins. Caudal part of azygos line communicates with subcardinal vein opposite the inter-subcardinal anastomosis. Hence, the azygos vein begins as lumbar azygos vein on both sides. On the left side, the fate of the azygos line is different. The caudal part of left anterior cardinal vein, cranial part of left posterior cardinal vein and the left common cardinal vein retrogress considerably. Due to this, the left azygos line divides into upper and lower parts. Upper part forms the accessory hemiazygos vein and drains into azygos vein opposite seventh thoracic vertebra and the lower part is called hemiazygos vein and drains into azygos vein opposite eighth thoracic vertebra. Accessory hemiazygos vein receives $4^{\text {th }}$ to $6^{\text {th }}$ left posterior intercostal veins and the hemiazygos receives $7^{\text {th }}$ to $11^{\text {th }}$ posterior intercostal veins. Errors in the normal development can lead to anomalous pattern of azygos veins or even total absence of one of them. We report one such anomalous pattern of azygos system.

\section{Case Report}

During routine dissections we noted abnormal formation and tributaries of azygos system of veins in an adult male cadaver aged approximately 65 years. The azygos vein was formed by the union of lumbar azygos vein and right subcostal veins. The ascending lumbar vein did not join the azygos vein.
The right lumbar azygos arose from the posterior surface of inferior vena cava. The hemiazygos vein arose from the left renal vein and coursed upward and joined the azygos vein at the level of $7^{\text {th }}$ thoracic vertebra. There was no accessory hemiazygos vein. The azygos vein received right $4^{\text {th }}$ to $11^{\text {th }}$ right posterior intercostal veins and also received $3^{\text {rd }}$ to $6^{\text {th }}$ left posterior intercostal veins. Hemiazygos vein received $7^{\text {th }}$ to $11^{\text {th }}$ left posterior intercostal veins. The hemiazygos vein was larger in size compared to the lower part of azygos vein. It appeared as if the hemiazygos vein continued as azygos vein due to its large size. The variations can be seen in Figures 1-3.

\section{Discussion}

In the past, many variations of the azygos system of veins have been reported. Ozbek, Dalcik, Colak et al. (1999), have reported a case where the hemiazygos vein was completely absent. Absence of accessory hemiazygos vein has also been reported in a recent case report (SILVEIRA, SOUSA, SIQUEIRA et al., 2012) in which, $4^{\text {th }}$ to $6^{\text {th }}$ left posterior intercostal veins drained directly into the azygos vein. In the current case, the accessory hemiazygos vein was absent but only $3^{\text {rd }}$ to $6^{\text {th }}$ left posterior intercostal veins drained directly into azygos vein and the rest drained into hemiazygos vein. According to earlier reports the accessory hemiazygos and hemiazygos veins are underdeveloped in $15 \%$ of cases. The current case differs from previously published reports. There was no ascending lumbar vein in the current case. The lumbar azygos and subcostal veins united to form the azygos and hemiazygos veins. Another important observation is that the hemiazygos vein was larger than its counterpart on the right side and appeared to continue as azygos vein after crossing the $7^{\text {th }}$ thoracic vertebra from left to right. The lower part of azygos vein below the level of seventh thoracic vertebra appeared like a tributary of the hemiazygos vein. 


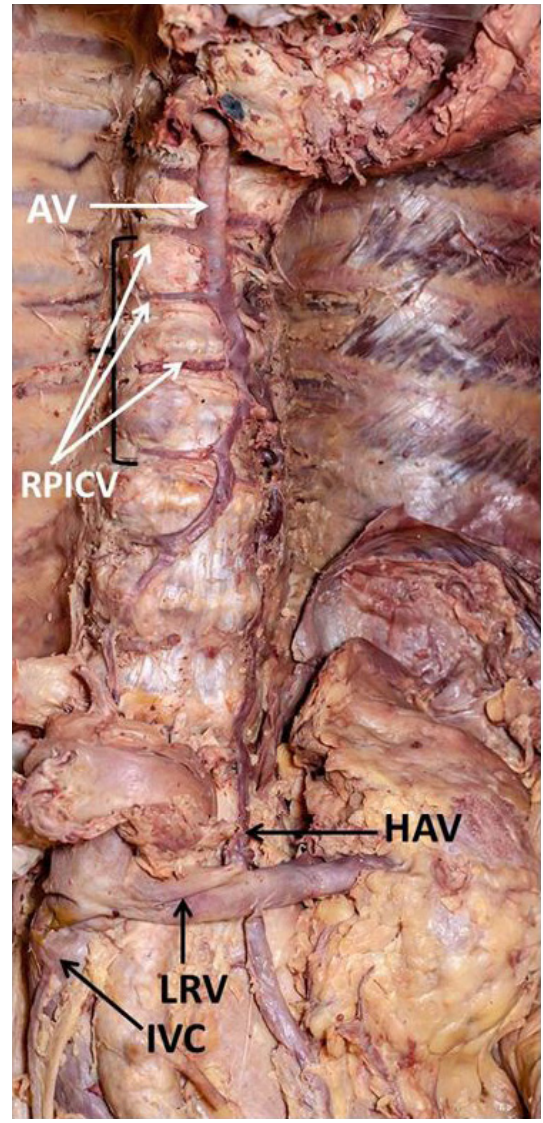

Figure 1. Dissection of posterior thoracic wall showing azygos vein and tributaries. AV - azygos vein; RPICV - right posterior intercostal veins; HAV - hemiazygos vein; LRV - left renal vein; IVC - inferior vena cava).

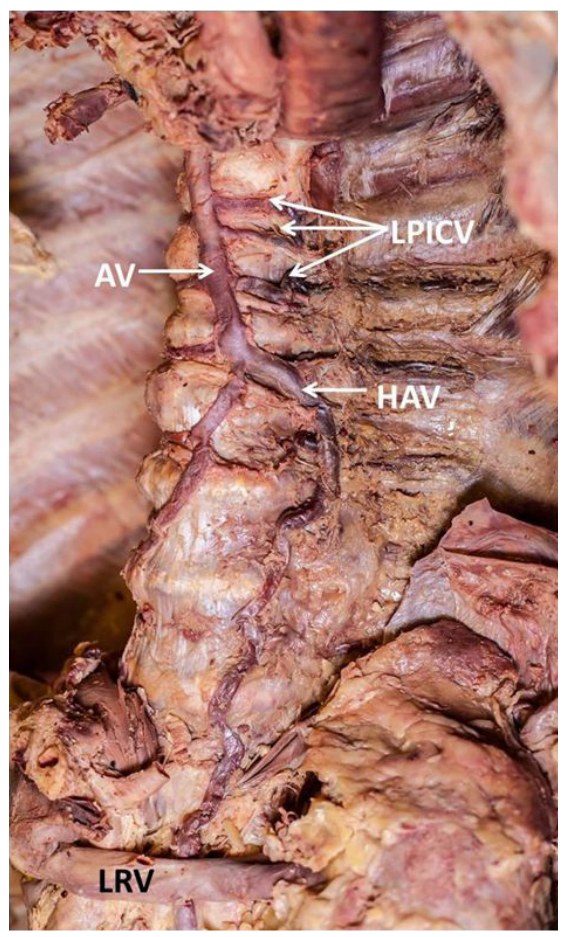

Figure 2. Dissection of posterior thoracic wall showing hemiazygos vein and tributaries. AV - azygos vein; LPICV - left posterior intercostal veins; HAV - hemiazygos vein; LRV - left renal vein.

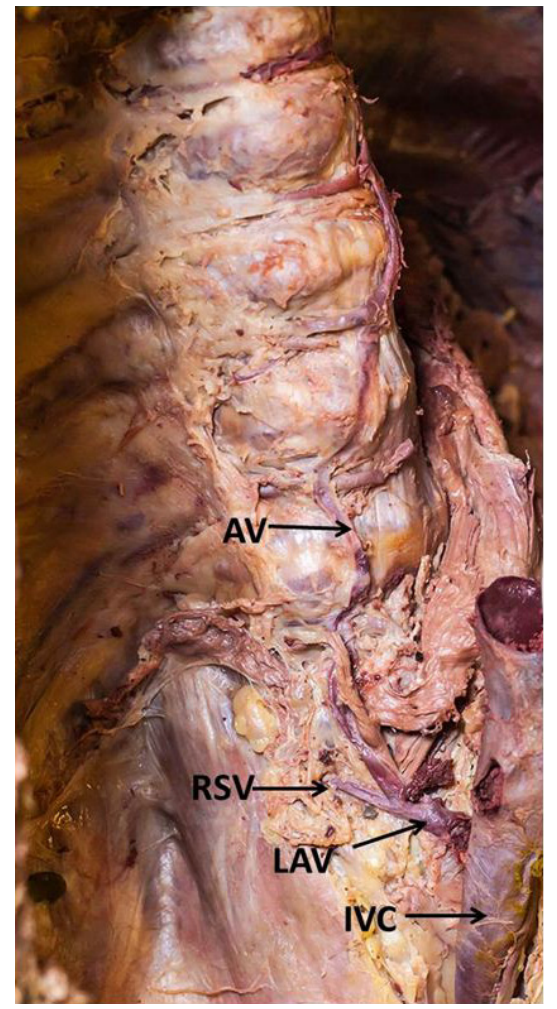

Figure 3. Dissection of posterior thoracic wall showing origin of azygos vein. AV - azygos vein; RSV - right subcostal vein; LAV - left ascending lumbar vein; IVC - inferior vena cava.

The variant azygos and hemiazygos veins may cause confusions during endoscopic thoracic sympathectomy (SIEUNARINE, MAY, WHITE et al., 1997) and in interpreting CT scan images (TAKASUGI and GODWIN, 1990). The variant veins may appear like lymphadenopathy, tumors or aneurisms. Though the anatomical variations of the azygos system are functionally normal, it is a must to be aware of their unique yet normal variations to prevent their iatrogenic injuries and inadvertent hemorrhagic complications (BRENER, DARLING, FREDERICK et al., 1974).

\section{Conclusion}

Knowledge of possible variations of azygos system of veins is of importance to surgeons while dealing with posterior mediastinal structures. It is also of utmost importance to the radiologists while interpreting the CT and MRI images.

\section{References}

BRENER, BJ., DARLING, RC., FREDERICK, PL. and LINTON, RR. Major venous anomalies complicating abdominal aortic surgery. Archives of Surgery, 1974, vol. 108, n. 2, p. 159-165. PMid:4810520. http://dx.doi.org/10.1001/archsurg.1974.01350260019004.

COSCINA, WF., ARGER, PH., MINTZ, MC. and COLEMAN, BG. Concurrent duplication and azygos continuation of the inferior vena cava. Journal of Computer Assisted Tomography, 1986, vol. 10, n. 3, p. 287-290. PMid:3731816. http://dx.doi.org/10.1016/0149936X(86)90057-3. 
MEZZOGIORNO, A. and PASSIATORE, C. An atypic pattern of the azygos venous system in man. Anatomischer Anzeiger, 1988, vol. 165, n. 4, p. 277-281. PMid:3400891.

ÖZBEK, A., DALCIK, C., COLAK, T. and DALÇIK, H. Multiple variations of the azygos venous system. Surgical and Radiologic Anatomy, 1999, vol. 21, n. 1, p. 83-85. PMid:10370999. http:// dx.doi.org/10.1007/BF01635060.

PILLET, J., MERCIER, P., CRONIER, P., MOREAU, P., LESCALIE, F., CHEVALIER, JM., ENON, B., JAEGER, JF., CARON POITREAU, C. and RIEUX, D. Isolated azygos continuation of the inferior vena cava. Absence of the retrohepatic segment of the inferior vena cava. Bulletin de l'Association des Anatomistes, 1986, vol. 70, n. 210, p. 69-74. PMid:3327548.

SIEUNARINE, K., MAY, J., WHITE, GH. and HARRIS, JP. Anomalous Azygos Vein: a potential danger during endoscopic thoracic sympathectomy. The Australian and New Zealand Journal of Surgery, 1997, vol. 67 , n. 8, p. 578-579. PMid:9287933.

SILVEIRA, D., SOUSA, LM., SIQUEIRA, SL., OLIVEIRA, BVM., SILVA, AT., COSTA, JP., ARAÚJO, DC., COSTA, GAR. and ARAÚJO, BA. Anatomic variation of thorax drainage:absence of accessory hemiazygos vein. Brazilian Journal of Morphological Sciences, 2012, vol. 29, n. 2, p. 94-95.

TAKASUGI, JE. and GODWIN, JD. CT appearance of the retroaortic anastomoses of the azygos system. AJR. American Journal of Roentgenology, 1990, vol. 154, n. 1, p. 41-44. PMid:2104722.

Received December 3, 2015

Accepted March 19, 2017 